\title{
Determination and Risk Assessment of Formaldehyde and Acetaldehyde in the Ambient Air of Gas Stations in Salvador, Bahia, Brazil
}

\author{
Lícia P. S. Cruz, ${ }^{(* *, a}$ Sâmeque R. Luz, ${ }^{a}$ Vânia P. Campos, ${ }^{a}$ Franciele O. Santana ${ }^{a}$ and \\ Raiane S. Alves ${ }^{a}$ \\ ${ }^{a}$ Departamento de Química Analítica, Instituto de Química, Universidade Federal da Bahia, \\ 40170-115 Salvador-BA, Brazil
}

\begin{abstract}
Formaldehyde (FA) and acetaldehyde (AA) were determined in the ambient air of five gas stations (GS) in the city of Salvador, Bahia State, Brazil, using three passive samplers exposed simultaneously for $8 \mathrm{~h}$ and analysis by high-performance liquid chromatography-ultraviolet detection (HPLC-UV). The concentration ranges found were 3.31-5.78 $\mu \mathrm{g} \mathrm{m}^{-3}$ for FA and $10.5-28.2 \mu \mathrm{g} \mathrm{m}^{-3}$ for AA. These values were below the exposure limits recommended by national and international agencies for occupational environments, however, FA concentrations were above the more restrictive limit $\left(3.30 \mu \mathrm{g} \mathrm{m}^{-3}\right)$ stablished by Texas Commission on Environmental Quality (TCEQ) for long-term outdoor exposure. The lifetime cancer risks (LCR) found associated with the exposure of GS employees to these aldehydes over the 30-year period varied between $4.51 \times 10^{-6}-8.00 \times 10^{-6}$ for FA and $2.46 \times 10^{-6}-6.60 \times 10^{-6}$ for AA. These values are above the acceptable limit set by the USEPA $\left(1.0 \times 10^{-6}\right)$, reinforcing the need for actions to minimize the occupational exposure, mainly to FA, which is associated with nasopharyngeal cancer.
\end{abstract}

Keywords: aldehydes, gas stations, passive sampling, health risks, occupational exposure

\section{Introduction}

Air quality in occupational environments, including gas stations (GS), has become a research subject because of the need to evaluate the possible risks to workers' health due to the long time they are exposed to polluted air in the workplace. ${ }^{1}$ In Brazil, the GS are establishments which carry out resale activities of different fuels, such as diesel with addition of biodiesel, compressed natural gas, hydrous ethyl alcohol (HEA) and anhydrous ethanol-gasoline blends (gasohol), with equipment and facilities available for measuring and storing these fuels. ${ }^{2}$ According to the National Petroleum, Natural Gas and Biofuels Agency of Brazil (ANP), ${ }^{3}$ a total of 41,984 GS were installed until 2017 in Brazil, being São Paulo the first and Bahia the fifth state with the largest number of GS in operation.

In these occupational environments, the workers are exposed daily to various volatile hazardous fuels, usually without using personal protective equipment, via different routes of absorption, as dermal absorption, ingestion and mainly by inhalation. ${ }^{4-6}$ Two previous studies ${ }^{4,5}$ were performed in Brazilian GS, indicating a strong correlation

*e-mail: lila@ufba.br between symptoms of volatile organic compounds (VOCs) intoxication and inadequate occupational habits reported by the GS workers, such as: smelling the fuel tank cap, using flannel when filling the tank, suctioning fuel from the tank with a hose, placing the face near the fuel tank, and wetting clothes with fuel. These results showed that although inhalation was the major route exposure of GS workers to absorption of VOCs, it is also important to consider accidental ingestion and dermal absorption in these occupational environments.

Gasoline, an important petroleum product, consists of a complex mixture of VOCs ranging from 4 to 12 carbon atoms with boiling points between 30 to $220^{\circ} \mathrm{C}$, consisting mainly of hydrocarbons belonging to the paraffin classes (normal and branched), olefins, naphthenics and aromatics, and to a lesser extent compounds with oxygen and sulfur. ${ }^{7}$ In Brazil, it is the second most consumed fuel and can be type A or C. Type A gasoline is derived from refineries and is generally not commercialized due to its low number of octanes. In order to be sold at GS, gasoline A is mixed with anhydrous ethyl alcohol used as anti-knock additive, in the proportions defined by legislation ${ }^{8}$ (currently $25-27 \% \mathrm{v} / \mathrm{v}$ ). After being mixed with the additive, it is then called type C gasoline. ${ }^{9}$ 
Among various VOCs, aromatic hydrocarbons as benzene, toluene, ethylbenzene and xylene isomers, known as the BTEX group, as well as aldehydes, mainly formaldehyde (FA) and acetaldehyde (AA), are the most extensively studied in these occupational environments due to adverse health effects on workers, from nausea, headaches, cough, allergies, eye and respiratory tract irritations, to serious chronic diseases such as asthma and cancer. ${ }^{10-15}$ Benzene is classified as carcinogenic to humans (group 1) and is associated with myeloid leukemia, FA is also classified in group 1 and may cause nasopharyngeal cancer in humans, while ethylbenzene and AA are classified in group 2B (probable human carcinogen) by the International Agency for Research on Cancer (IARC)..$^{12-15}$ Thus, exposure to these compounds in GS increases probability of cancer risk for the workers.

VOCs form an important group of atmospheric pollutants emitted in GS mainly due evaporation of the gasoline and gasoline-oxygenated fuels blends during fuel supply activities, tanks filling and vapors leakage from storage tanks and vehicle fuel tanks, besides vehicles combustion..$^{10,11,16}$ Previous studies ${ }^{17,18}$ have shown that although the exhaust pipe emissions from combustion are currently much cleaner, due to the development of new technologies and advanced after-treatment systems, the use of oxygenated fuels blends with gasoline makes evaporative emissions an important source of methanol, ethanol, aldehydes and other VOCs, as a result of the increased vapor pressure of these mixtures when compared to pure gasoline. FA and AA emissions to the atmosphere in Brazilian GS are also intensified by the use of oxygenated fuels, such as HEA and gasohol, ${ }^{19}$ since ethanol reacts with hydroxyl radicals $(\mathrm{OH})$ forming the corresponding hydroxyalkyl radicals, which then react with the oxygen producing aldehydes. ${ }^{20}$ Furthermore, some studies ${ }^{21,22}$ have shown that the addition of biodiesel in the traditional diesel in Brazil to obtain less polluting fuels has also caused an increase in aldehydes emissions into the atmosphere. These compounds also play a major role in atmospheric chemistry, as they result from the first photooxidation of hydrocarbons, for configuring the main source of free radicals, as well as being precursors of ozone and organic aerosol, mainly in urban areas. ${ }^{23}$

Formaldehyde and acetaldehyde are the two most abundant aldehydes in the atmosphere and are considered as primary and/or secondary pollutants. There is also a fraction of aldehydes (about 10\%) consisting of propionaldehyde, propanone, acrolein, benzaldehyde and others. ${ }^{23}$ The processes of aldehydes formation in the atmosphere through photochemical reactions involving the decomposition of hydrocarbons and other organic compounds contribute with 45 to $95 \%$ in relation to primary emissions, such as vehicle exhaust emissions, biomass burning, biofuels, fossil fuels and industrial processes. ${ }^{23}$ Regarding combustion processes, ethanol powered vehicles emit about $90 \%$ AA and $10 \%$ FA, while in diesel powered vehicles the emission is $70 \% \mathrm{FA}$ and $30 \% \mathrm{AA}$. On the other hand, the use of diesel/biodiesel and gasoline/anhydrous ethanol blends can increase these levels. ${ }^{16,24}$

Sampling of FA and AA in the air of occupational environments and outdoor areas is generally performed by using active techniques where air is sucked into a sampling device with the aid of a vacuum pump, requiring batteries or a power line, in addition to air flow meters. An alternative and viable air sampling technique for atmospheric monitoring, including occupational environments, is the passive sampling based on physical processes such as diffusion and permeation, without involving the active movement of air through the sampler. The driving force of mass transport is the concentration difference from the external to the internal environments according to Fick's first law. The passive samplers used are small, lightweight, low cost, non-noisy, not depending on electricity and periodic calibrations, and results of the measurements show high accuracy and precision. ${ }^{1,25}$

Some studies have been conducted aiming to determine the FA and AA concentrations in the atmosphere $\mathrm{e}^{26-31}$ and to evaluate the potential risks to human health in urban areas. ${ }^{32-34}$ A study ${ }^{19}$ carried out in the Metropolitan Area of São Paulo, in southeastern Brazil, over four seasons in 2012 and 2013, had measured FA and AA concentrations using 2,4-dinitrophenylhydrazine (DNPH)-silica cartridges with the aid of a vacuum pump and analyzed with highperformance liquid chromatography (HPLC), according to U.S. Environmental Protection Agency (USEPA) method TO-11A (Active Sampling Methodology). ${ }^{35}$ The minimum and maximum atmospheric levels found were 5.8 and $35.3 \mu \mathrm{g} \mathrm{m}^{-3}$ for FA and 5.7 and $27.4 \mu \mathrm{g} \mathrm{m}^{-3}$ for AA, demonstrating that although there was an increase in the number of flex-fuel vehicles using gasoline and/or HEA in this area, there was no significant increase in the atmospheric concentrations of aldehydes when compared to previous studies, ${ }^{36}$ due to technological advances in vehicle emissions control.

In another study, ${ }^{26}$ carried out during rainy and dry periods of 2015 in urban areas of Salvador City, in northeastern Brazil, FA and AA were passively sampled with exposure for 7 or 14 days, using fiberglass filters impregnated with $30 \mathrm{mmol} \mathrm{L}^{-1}$ 2,4-DNPH solution $+1 \mathrm{~mol} \mathrm{~L}^{-1}$ glycerol, and subsequently determined by HPLC-ultraviolet (UV). The concentrations found in the atmosphere varied in the range of 2.3-4.8 $\mu \mathrm{g} \mathrm{m}^{-3}$ for FA and $<1.2-1.9 \mu \mathrm{g} \mathrm{m}^{-3}$ for AA during the rainy period; whereas $1.5-18 \mu \mathrm{g} \mathrm{m}^{-3}$ were found for FA and $<1.2-19 \mu \mathrm{g} \mathrm{m}^{-3}$ for AA in the dry period. These 
results indicated higher atmospheric levels of these aldehydes in summer than in winter, due to the higher photochemical oxidation of hydrocarbons in the period of higher solar incidence, besides the influence of direct emissions. In a subsequent study, ${ }^{32}$ carcinogenic risks to the population of Salvador City due to FA and AA exposure by inhalation were estimated over a 40 -year period. The values obtained were above the limit established as acceptable $\left(1.0 \times 10^{-6}\right)$ by USEPA, either for FA, during dry and rainy periods, or for AA in dry period.

Few studies, including in Brazil,${ }^{37}$ have been reported in the literature on the determination of these compounds in the GS atmosphere, as well as the risk assessment associated with the health of workers. ${ }^{6,10,38-41}$ In a work carried out at gas stations in central Bangkok, Thailand, the TO-11A Method of the USEPA was also used for $8 \mathrm{~h}$ aldehyde sampling and subsequent determination of the analytes by HPLC-UV. ${ }^{41}$ The concentrations obtained varied within the range 7.56-18.83 $\mu \mathrm{g} \mathrm{m}^{-3}$ for FA and 2.15-13.11 $\mu \mathrm{g} \mathrm{m}^{-3}$ for $\mathrm{AA}$, and estimated lifetime cancer risks were above the limit established by USEPA, showing that workers at these occupational environments have high cancer risks through exposure by inhalation..$^{41}$ In another study ${ }^{10}$ using similar sampling and analysis methods, aldehydes concentrations in GS in Japan have been reported in the range of $3.9 \pm 1.5$ to $13 \pm 6.3 \mu \mathrm{g} \mathrm{m}^{-3}$ for FA and $9.9 \pm 5.0$ to $20 \pm 12 \mu \mathrm{g} \mathrm{m}^{-3}$ for AA considering personal exposure.
No studies have been found in the literature so far that passive sampling was used to monitor FA and AA in the ambient air of gas stations. The group of the Laboratory of Environmental Analytical Chemistry (LAQUAM) of the Federal University of Bahia (UFBA) has been developing and validating passive samplers for inorganic and organic compounds, ${ }^{25,26,42}$ with application in various types of environments, such as: forest, marine-coastal, urban, industrial, and more recently passive samplers for FA and AA have also been applied in occupational environments. In addition, considering the consequences of exposure to these compounds on the health of workers in GS, a risk assessment was also carried out in this study.

Thus, the objective of this study was to determine the concentrations of FA and AA in the ambient air of five GS in the city of Salvador, Bahia, Brazil, using passive sampling and analysis by HPLC-UV, in addition to evaluating the health risks to workers associated with occupational exposure to these aldehydes by inhalation.

\section{Experimental}

\section{Sampling}

Samplings for determination of FA and AA in ambient air from five selected GS in the city of Salvador, capital of Bahia, in the Northeast region of Brazil (Figure 1a) was
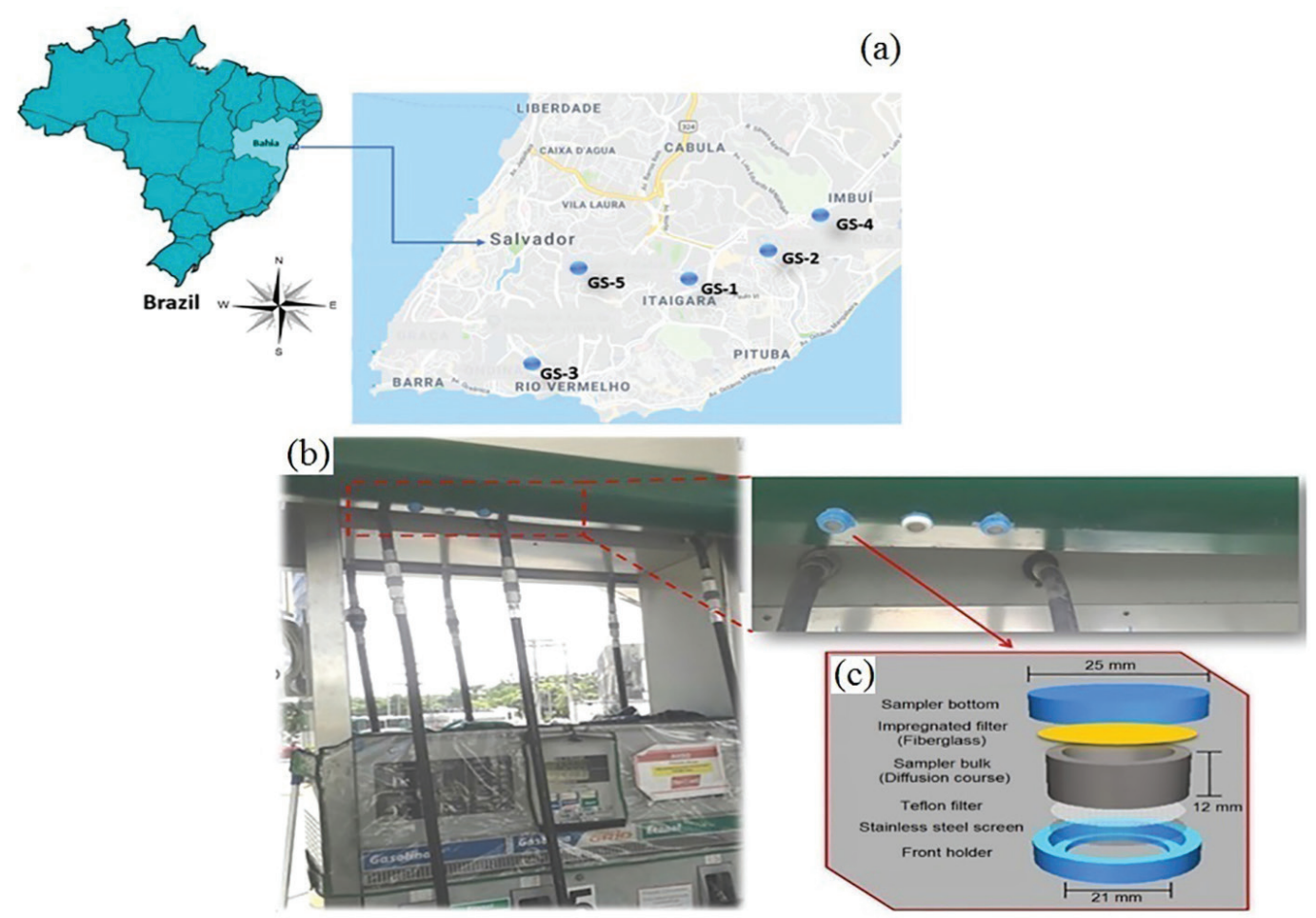

Figure 1. Location of five selected gas stations (GS) in the city of Salvador (a); passive sampling of aldehydes at one of the GS (b) and passive sampler scheme used in this study (c). 
performed in the periods from 25 to 26 May and 06 to 08 June 2017, between 09:00 a.m. and 05:00 p.m., corresponding to the shift work with the highest consumption of fuels. A daily sampling was carried out in each of the five GS, selected also taking into account the high volume of fuels sold in these establishments, due to the large number of vehicles circulating in nearby areas, in addition to the permission to access the sites and the safety conditions for the exposure of passive samplers. The weather conditions during the samplings were about $23.7^{\circ} \mathrm{C}$ temperature, $7 \mathrm{~mm}$ rainfall and $76 \%$ relative humidity. The gas stations GS1, GS2 and GS3 are located in commercial areas with congested traffic and their surroundings include hospitals, medical centers, schools, universities, shopping centers and other commercial establishments. GS4 and GS5 are located in residential areas with intense vehicle traffic.

The diffusive passive samplers used in this study for the sampling of FA and AA were developed and validated locally ${ }^{26}$ and they consist of a polyethylene cylindrical tube (12 mm height, 21 and $25 \mathrm{~mm}$ internal and external diameters, respectively) closed at the bottom, containing a Teflon membrane (Millipore, polytetrafluoroethylene (PTFE), $0.5 \mu \mathrm{m}$ pore, hydrophobic) at the air inlet, followed by a stainless steel screen $(0.08 \mathrm{~mm}$ thread diameter and $0.125 \mathrm{~mm}$ mesh size); after the diffusion space there is a glass fiber filter (Millipore) impregnated with specific reagent to fix the diffuse gases through the sampler (Figure 1c).

The use of these passive samplers (PS) is advantageous because of simplicity and low cost, besides allowing reuse of all parts except the filters. Additionally, it allows the use of different absorption reagents for filter impregnation, the reduction of gases residence time inside the sampler due to their short diffusion path and minimizes the effects of turbulent diffusion. ${ }^{25}$

For the preparation of the PS, glass fiber filters were cut in the diameter of $25 \mathrm{~mm}$ for adaptation to the bottom of the passive sampler. All parts of the PS were washed three times with 2\% Extran neutral detergent (Merk, Darmstadt, Germany), rinsed with deionized water and ethanol, and then dried in an oven at $50{ }^{\circ} \mathrm{C}$. In order to impregnate the filters, aliquots of $200 \mu \mathrm{L}$ of the solution (30 mmol L ${ }^{-1} 2,4-\mathrm{DNPH}+1.0 \mathrm{~mol} \mathrm{~L}^{-1}$ glycerol) were added with micropipettes. Subsequently, the filters were dried in a desiccator containing silica gel for $24 \mathrm{~h}$. After this procedure, the samplers were mounted, sealed with flexible film, properly identified and sent for sampling.

The reagent most commonly used to impregnate the aldehydes collection medium is 2,4-DNPH, due to its stability and well-established methodology for derivatization, which is necessary due to high activity, high polarity and chemical instability of aldehydes. ${ }^{26,43}$ Aldehydes combine with 2,4-DNPH through a nucleophilic addition reaction of the carbonyl group to form stable hydrazones (carbonyl hydrazones), which are subsequently extracted from the collection medium ${ }^{44}$ (Scheme 1).

In each GS, 3 PS were exposed simultaneously for periods of $8 \mathrm{~h}$ (equal to the working day of the workers), together the fuel pumps most required by consumers, at a height of approximately $2 \mathrm{~m}$ (Figure 1b). After the exposure period, the PS were sealed with Parafilm and taken to the laboratory for immediate analysis. To assess the occurrence of contamination during preparation, transport or analysis, fully sealed PS were used as field blanks.

Simultaneous passive and active measurements of aldehydes were compared using diffusive passive samplers containing fiberglass filters impregnated with $30 \mathrm{mmol} \mathrm{L}^{-1} 2,4-\mathrm{DNPH}+1 \mathrm{~mol} \mathrm{~L}^{-1}$ glycerol solution, and 2,4-DNPH-silica cartridges with a scrubber to avoid ozone interference. ${ }^{26}$ The results showed excellent correlation between the measurements, thus indicating that there was no significant interference of ozone, and presenting high efficiency of passive sampling for aldehydes when compared with the active measurement.

\section{Analysis and quality control}

Each filter containing the aldehydes fixed as hydrazones was transferred from the passive sampler to a $5 \mathrm{~mL}$ borosilicate vial with a polypropylene cap and PTFE/silicone septum, previously decontaminated with acetonitrile (ACN). Figure 2 shows the extraction steps of the analytes for further separation and quantification by HPLC, model 1220 Infinity LC System (Agilent Technologies), with a UV detection at $360 \mathrm{~nm}$. The separation column was Zorbax ODS $5 \mu \mathrm{m}, 4.6 \times 250 \mathrm{~mm}$, and the mobile phase was $60 \%$ $\mathrm{ACN} / \mathrm{H}_{2} \mathrm{O}$, at a flow rate of $1.5 \mathrm{~mL} \mathrm{~min}{ }^{-1}$.

Calibration curves for FA and AA were based on the external standardization method and were constructed

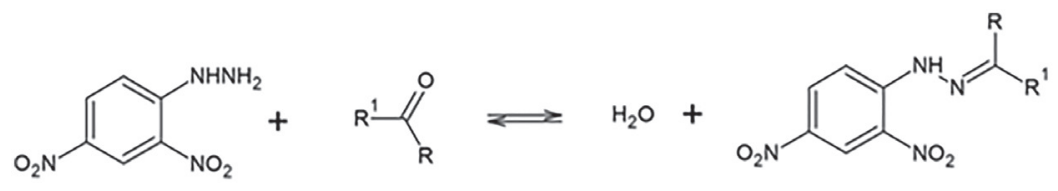

$\mathrm{R}^{1}$ and $\mathrm{R}=$ Radicals

Scheme 1. Derivatization reaction of aldehydes with 2,4-dinitrophenylhydrazine. 


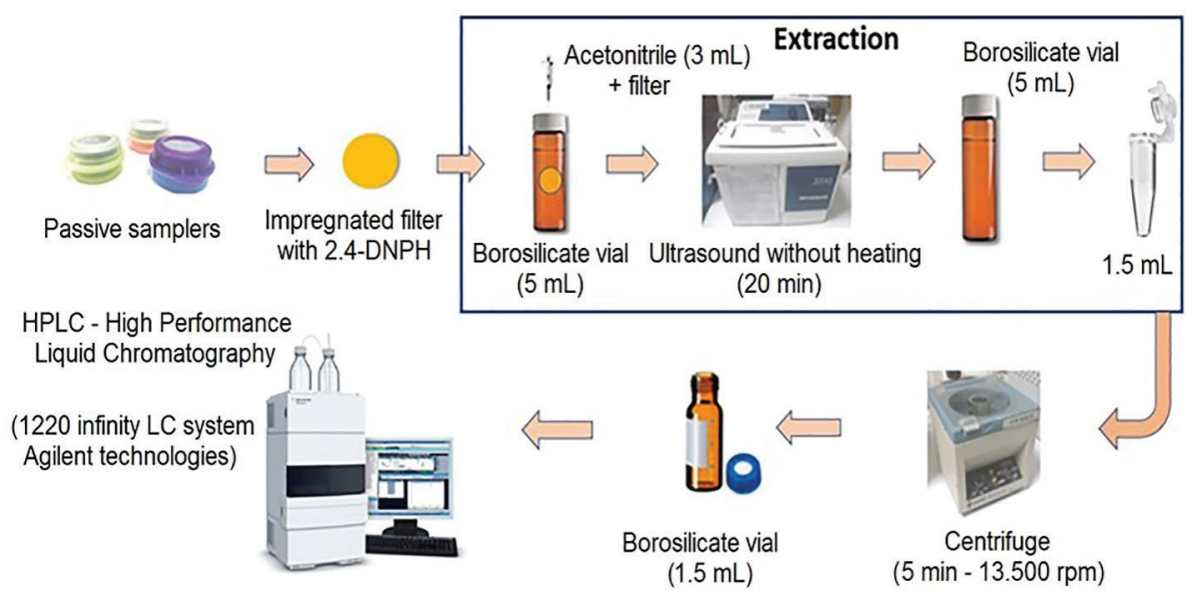

Figure 2. Stages of analytes extraction and analysis by HPLC-UV.

from dilution in acetonitrile of $1.0 \mu \mathrm{g} \mathrm{mL} \mathrm{m}^{-1}$ aldehyde/ ketone-DNPH (Sigma-Aldrich Brazil Ltda, São Paulo, Brazil) standard solution. They were composed of seven points, with a linear dynamic range between 1.0-150 $\mu \mathrm{g} \mathrm{L} \mathrm{L}^{-1}$. The regression equation for each calibration curve was calculated using the linear regression method. Calibration results demonstrated good linearity for both analytes with the following correlation coefficients $(\mathrm{R})$ : FA $(\mathrm{R}>0.9998)$ and AA ( $R>0.9995)$. The values of limits of detection (LOD) and quantification (LOQ) were determined by the statistical analysis of data, and the following values were obtained: 1.62 and $3.78 \mu \mathrm{g} \mathrm{L}{ }^{-1}$ for FA, and 0.36 and $1.19 \mu \mathrm{g} \mathrm{L} \mathrm{L}^{-1}$ for AA, respectively.

\section{Risks assessment}

Risk assessment can be defined as the estimation of adverse effects on human health associated with exposure to environmental agents, whether physical, chemical or biological. Potential health risks, such as cancer and non-cancer risks, can be evaluated using different methods adopted by international agencies. The non-carcinogenic risk assessment by inhalation is based on the comparison of pollutant concentrations with their respective chronic non-carcinogenic levels. These are expressed as minimum risk levels (MRLs) by the Agency for Toxic Substances and Disease Registry (ATSDR), ${ }^{45}$ reference exposure levels (RELs) by the California Office of Environmental Health Hazard Assessment (OEHHA), ${ }^{46}$ or reference concentrations (RfCs) by the Integrated Risk Information System (IRIS) of the US Environmental Protection Agency (USEPA) ${ }^{47}$

Cancer risk is usually estimated by lifetime cancer risk (LCR), which is presented as the increased probability of developing cancer as a result of a specific exposure. ${ }^{48}$ The cancer risks by inhalation of pollutants can be evaluated according to the standard method of the USEPA, ${ }^{49,50}$ and the cancer risk of occupational exposure to pollutants by inhalation, dermal contact and non-dietary ingestion for workers can be evaluated according to the method of the American Conference of Governmental Industrial Hygienists (ACGIH). ${ }^{51}$ The ACGIH provides threshold limit values (TLV) based on short-term exposure limit and time-weighted average (TWA) standards of 8-h workday or 40-h workweek. Therefore, this agency only assesses cancer risk related to occupational exposure. ${ }^{52}$

To estimate the health effects on workers in GS due to exposure to FA and AA by inhalation, the risk assessment indicators used included the LCR and the non-carcinogenic risk, expressed as a hazard quotient (HQ), following the standard method of the USEPA. ${ }^{49,50}$ This risk assessment method is a comprehensive approach as it considers many factors that may affect exposure, such as duration and frequency of exposure, inhalation rate, body weight, average lifetime of target population and concentration of the pollutants. Hence, this method was chosen for application in this study. Table 1 presents the parameters used to calculate these risks.

The doses in the period of exposure, expressed as chronic daily intake (CDI) or chronic daily intake yearly $\left(\mathrm{CDI}_{\mathrm{Y}}\right)$, were calculated according to equations 1 and 2:

$$
\begin{aligned}
& \mathrm{CDI}=\frac{\mathrm{C} \times \mathrm{IR} \times \mathrm{ED}}{\mathrm{BW}} \\
& \mathrm{CDI}_{\mathrm{Y}}=\mathrm{CDI} \frac{\mathrm{D}}{7} \frac{\mathrm{EF}}{52}
\end{aligned}
$$

where $\mathrm{C}$ is the exposure concentration, IR is the inhalation rate, $\mathrm{ED}$ is the exposure duration, $\mathrm{BW}$ is the body weight, $\mathrm{D}$ is days of work, and EF is the exposure frequency.

From the value of chronic daily intake yearly $\left(\mathrm{CDI}_{Y}\right)$ and the reference dose of inhalation of the specific air 
Table 1. Parameters used in the calculation of non-cancer and cancer risks in this study

\begin{tabular}{|c|c|c|}
\hline Parameter & Description & Value \\
\hline $\mathrm{C}$ & exposure concentration / $\left(\mathrm{mg} \mathrm{m}^{-3}\right)$ & - \\
\hline IR & inhalation rate, adult / $\left(\mathrm{m}^{3} \mathrm{~h}^{-1}\right)$ & 0.83 \\
\hline $\mathrm{ED}$ & exposure duration, adult / $\left(\mathrm{h}\right.$ day $\left.^{-1}\right)$ & 8 \\
\hline $\mathrm{EF}$ & exposure frequency / (week year ${ }^{-1}$ ) & 48 \\
\hline $\mathrm{L}$ & length of exposure / year & 30 \\
\hline ATL & average lifetime / year & 75 \\
\hline BW & body weight / kg & 70 \\
\hline NY & number of days per year / day & 365 \\
\hline $\mathrm{D}$ & days of work / day & 6 \\
\hline $\mathrm{SF}_{\text {Formaldehyde }}$ & slope factor $/\left(\mathrm{mg} \mathrm{kg}^{-1}\right.$ day $\left.^{-1}\right)$ & 0.0455 \\
\hline $\mathrm{SF}_{\text {Acetaldehyde }}$ & slope factor $/\left(\mathrm{mg} \mathrm{kg}^{-1} \mathrm{day}^{-1}\right)$ & 0.0077 \\
\hline $\operatorname{RfD}_{\text {Formaldehyde }}$ & reference dose to formaldehyde / $\left(\mathrm{mg} \mathrm{kg}^{-1}\right.$ day $\left.^{-1}\right)$ & 0.20 \\
\hline $\operatorname{RfC}_{\text {Acetaldehyde }}{ }^{\text {a }}$ & reference dose to acetaldehyde / $\left(\mathrm{mg} \mathrm{m}^{-3}\right)$ & 0.0090 \\
\hline
\end{tabular}

${ }^{a}$ Reference concentration. The EPA did not establish a reference dose (RfD) for acetaldehyde.

pollutant (RfD), a level below the one in which adverse health effects are unlikely to occur, it is possible to estimate non-carcinogenic effects on human health by calculating $\mathrm{HQ}$, according to equation 3. In accordance with the IRIS, ${ }^{53,54}$ the RfD values for FA and AA are shown in Table 1.

$\mathrm{HQ}=\frac{\mathrm{CDI}_{\mathrm{Y}}}{\mathrm{RfD}}$

Values of HQ $\leq 1$ indicate an insignificant risk (acceptable level), while HQ values $>1$ correspond to exposure that is likely to cause adverse health effects. ${ }^{49}$

LCR is defined as the highest probability of cancer incidence by a continuous lifetime exposure to a specific compound. LCR was estimated using the chronic daily intake lifetime $\left(\mathrm{CDI}_{\mathrm{L}}\right)$, obtained through equation 4 :

$\mathrm{CDI}_{\mathrm{L}}=\frac{\mathrm{C} \times \mathrm{IR} \times \mathrm{ED} \times \mathrm{EF} \times \mathrm{L}}{\mathrm{BW} \times \mathrm{ATL} \times \mathrm{NY}}$

where $\mathrm{L}$ is the length of exposure, ATL is the average lifetime, and NY is the number of days per year.

Then, LCR was calculated by multiplying the $\mathrm{CDI}_{\mathrm{L}}$ value by a carcinogenicity factor, also called the slope factor (SF), according to equation 5. Values of SF for FA and AA are shown in Table $1 .^{55}$

$\mathrm{LCR}=\mathrm{CDI}_{\mathrm{L}} \times \mathrm{SF}$

LCR values $>1.00 \times 10^{-6}$ indicate positive results for carcinogenic effects, whereas LCR values $\leq 1.00 \times 10^{-6}$ are considered acceptable. ${ }^{49}$

\section{Results and Discussion}

Concentrations of formaldehyde and acetaldehyde in the ambient air of the gas stations

The values of the average concentrations for FA and AA found in the GS participating in this study are presented in Figure 3. The results show that for a sampling period of $8 \mathrm{~h}$, concentrations of formaldehyde and acetaldehyde are in the range of 3.26-5.8 and 10.5-28.2 $\mu \mathrm{g} \mathrm{m}^{-3}$, respectively. In GS1, the highest concentration levels of these compounds were observed, whereas in GS5 there were the lowest concentrations.

The different concentrations found can be related to several factors such as: fuel sales amount in each GS, flow of vehicles in the neighborhood, presence of high buildings nearby that hinder the dispersion of vapors, among others. Among these factors, the volume of fuel sold is one of the most significant, once during the fueling of vehicles there is a greater contribution by releasing fuel vapors, and when total evaporation occurs, the volume of air is exactly equal to the volume of fuel pumped. The volume of air released is directly proportional to the fuel volume, which probably influences the concentration levels found. ${ }^{56}$ The gas stations GS1, GS2 and GS4 stand out among other GS in this study for the highest volumes of commercialized fuels (> 800,000 L month ${ }^{-1}$ ), showing a close relationship with the highest levels of formaldehyde and acetaldehyde concentration found in the ambient air of these GS.

Results obtained in this study were compared with recommended exposure limits by Regulatory Standard NR-15 of the Brazilian Ministry of Labor and Employment, ${ }^{57}$ and by international agencies such as by 


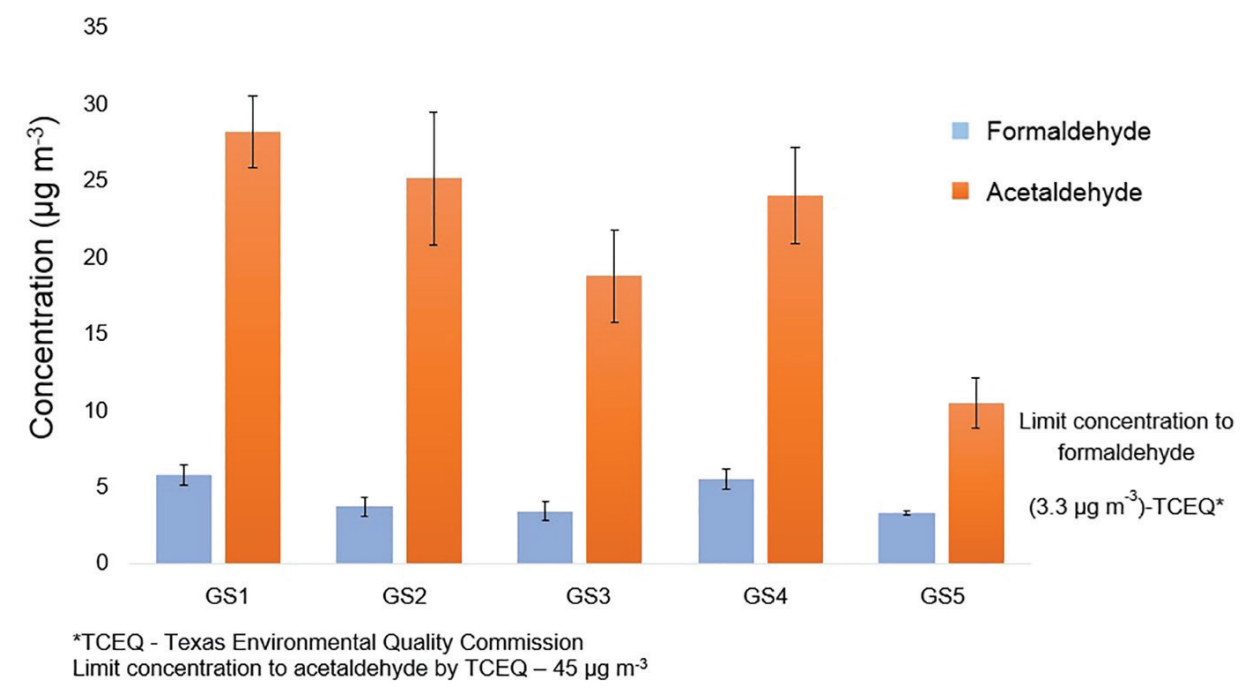

Figure 3. Average concentrations and standard deviations of formaldehyde and acetaldehyde in the studied gas stations.

the National Institute for Occupational Safety and Health $(\mathrm{NIOSH})^{58}$ and by $\mathrm{ACGIH}^{59}$ to occupational environments, besides limits values for long and short exposure established by Texas Commission on Environmental Quality (TCEQ) ${ }^{60}$ in outdoors (Table 2).

The FA and AA concentrations determined in the GS studied are below the exposure limits recommended by the Brazilian standard NR-15, ${ }^{57}$ American Conference of Governmental Industrial Hygienists (ACGIH) ${ }^{59}$ and by the $\mathrm{NIOSH}^{58}$ as well. However, when comparing the FA concentrations obtained in this study with the limit established by $\mathrm{TCEQ}^{60}$ for long exposure $\left(3.30 \mu \mathrm{g} \mathrm{m}^{-3}\right)$ in outdoor environments, it was verified that in all GS the concentrations were equal to or above this limit (Figure 3). This evaluation corroborates the need to implement actions for minimizing the exposure of workers to these compounds, especially to FA. Furthermore, risks due to chronic exposure of workers in GS should also be considered.

\section{Comparison with other studies}

Figure 4 shows the average concentrations of FA and AA found in this study compared to other studies carried out in gas stations. In this study, AA was the most prevalent aldehyde followed by FA, which was the opposite of results found in few studies carried out in Fortaleza (Brazil), ${ }^{37}$ Bangkok (Thailand) ${ }^{6,39}$ and Kolkata (India) ${ }^{38}$ gas stations. Due to the diversity of the sites, the variations in average aldehydes concentrations can also be attributed to seasonal influences, as well as differences in the composition of fuels used and in the volumes sold, besides the different methods of sampling and analysis.

According to data from the National Petroleum Agency (ANP), ${ }^{61}$ from the year 2016 to 2018 , consumption of hydrous ethyl alcohol (HEA) decreased 56\% in Brazil. However, in the state of Bahia, in contrast to the national average, consumption of HEA increased $34 \%$ in the same period, confirming that the population of this state has also used HEA as a fuel option in the light vehicle fleet. In addition, there was an increase in the content of anhydrous ethanol added to gasoline in Brazil, from 2015. ${ }^{8}$ These facts help to justify the results found in this study with AA values higher than the FA values, compared to those obtained in Fortaleza City, in 2012, where the FA concentrations were higher than those of AA in the gas stations. ${ }^{37}$ Besides, in this study the samples were collected during the day, and the

Table 2. Statistical summary (maximum, minimum and average) of the formaldehyde and acetaldehyde concentrations in ambient air of the studied gas stations and exposure limits established by NR-15, NIOSH, ACGIH and TCEQ

\begin{tabular}{|c|c|c|c|c|c|c|c|c|}
\hline \multirow{3}{*}{ Aldehyde } & \multicolumn{8}{|c|}{ Concentration / $\left(\mu \mathrm{g} \mathrm{m}^{-3}\right)$} \\
\hline & \multirow{2}{*}{ Maximum } & \multirow{2}{*}{ Minimum } & \multirow{2}{*}{ Average } & \multirow{2}{*}{$\mathrm{NR}-15^{57}$} & \multirow{2}{*}{$\mathrm{NIOSH}^{58}$} & \multirow{2}{*}{$\mathrm{ACGIH}^{59}$} & \multicolumn{2}{|c|}{$\mathrm{TCEQ}^{60}$} \\
\hline & & & & & & & Short exposure & Long exposure \\
\hline Formaldehyde & 5.78 & 3.26 & 4.34 & 2300 & 20 & 370 & 15 & 3.3 \\
\hline Acetaldehyde & 28.17 & 10.49 & 12.23 & 140000 & 32400 & 45000 & 90 & 45 \\
\hline
\end{tabular}

NR-15: regulatory standard of the Brazilian Ministry of Labor and Employment; NIOSH: National Institute for Occupational Safety and Health; ACGIH: American Conference of Governmental Industrial Hygienists; TCEQ: Texas Environmental Quality Commission. 


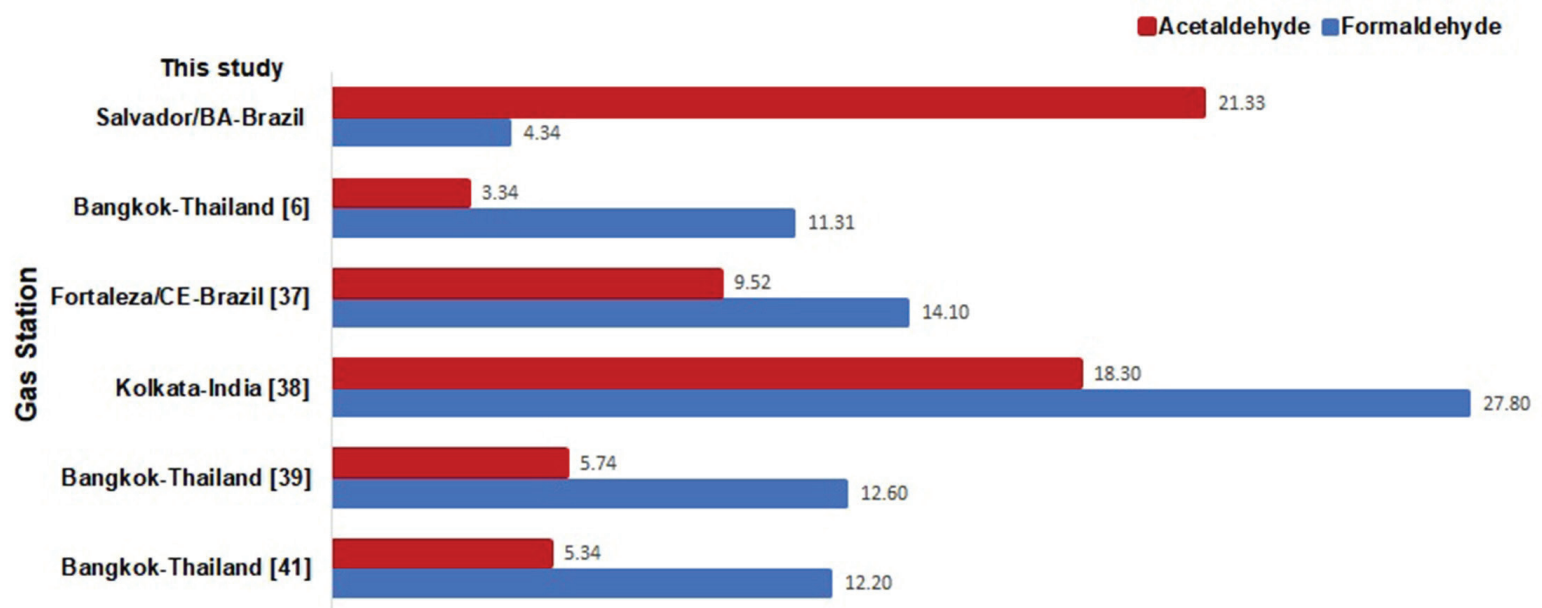

Average Concentration $\left(\mathrm{\mu g} \mathrm{m}^{-3}\right)$

Figure 4. Average concentrations of formaldehyde and acetaldehyde in gas stations of other localities compared to this study.

FA photolysis rate is faster than that reported for AA during this same period, when solar radiation and photochemical activity are intense, resulting in lower levels of FA than those registered for AA.

Comparing the results with those obtained in urban areas, where the use of oxygenated fuels is not common, formaldehyde is the predominant species, ${ }^{62-64}$ since this compound is more associated with gasoline engine emissions than acetaldehyde,${ }^{64}$ and the ratios between the concentrations of these two compounds (FA/AA) were higher than 1. In Brazilian cities, results from previous studies $^{22,36}$ showed that FA/AA ratios were predominantly lower than 1 . This behavior was attributed to the use in the vehicle fleet of oxygenated fuels such as HEA and gasohol, in addition to diesel-biodiesel blends, which increases acetaldehyde emissions into the atmosphere. Currently, in the city of São Paulo, ${ }^{19,27}$ there is a predominance of formaldehyde in the atmosphere, and FA/AA ratio is usually higher than 1, reflecting a decrease in the use of HEA as fuel and an increase in the number of natural gas powered vehicles. However, in other cities as Rio de Janeiro and
Londrina, in southeastern and southern Brazil, respectively, recent studies have shown that acetaldehyde is the most abundant species among aldehydes in the atmosphere, revealing that the concentrations of these compounds in the atmosphere of these cities are predominantly influenced by the increase in light vehicles fleet predominantly composed of flex-fuel vehicles. ${ }^{29,65}$

Assessment of the health risks for workers associated with exposure to formaldehyde and acetaldehyde compounds

The values found of LCR and HQ for the health of the workers associated with exposure to FA and AA compounds by inhalation in the 5 GS investigated over a 30-year period are shown in the Table 3. The LCR values at all gas stations studied were above the acceptable limit by USEPA $\left(1.0 \times 10^{-6}\right),{ }^{49}$ indicating high carcinogenic risks, with values of 5-10 times higher for FA and 3-8 times higher for AA.

Similar results were reported in studies ${ }^{6,39-41}$ carried out in Bangkok (Thailand) for a 30-year exposure period, which determined LCR values ranging from

Table 3. Assessment of the health risks for workers by exposure to formaldehyde and acetaldehyde in the five gas stations studied

\begin{tabular}{|c|c|c|c|c|c|c|}
\hline \multirow{2}{*}{ Gas station } & \multicolumn{3}{|c|}{ Formaldehyde } & \multicolumn{3}{|c|}{ Acetaldehyde } \\
\hline & $\mathrm{CDI}_{\mathrm{L}}$ & HQ & LCR & $\mathrm{CDI}_{\mathrm{L}}$ & HQ & LCR \\
\hline GS1 & $1.76 \times 10^{-4}$ & $2.74 \times 10^{-3}$ & $8.00 \times 10^{-6}$ & $8.57 \times 10^{-4}$ & $2.97 \times 10^{-1}$ & $6.60 \times 10^{-6}$ \\
\hline GS2 & $1.13 \times 10^{-4}$ & $1.76 \times 10^{-3}$ & $5.13 \times 10^{-6}$ & $7.65 \times 10^{-4}$ & $2.65 \times 10^{-1}$ & $5.89 \times 10^{-6}$ \\
\hline GS3 & $1.04 \times 10^{-4}$ & $1.62 \times 10^{-3}$ & $4.72 \times 10^{-6}$ & $5.71 \times 10^{-4}$ & $1.98 \times 10^{-1}$ & $4.40 \times 10^{-6}$ \\
\hline GS4 & $1.68 \times 10^{-4}$ & $2.62 \times 10^{-3}$ & $7.65 \times 10^{-6}$ & $7.32 \times 10^{-4}$ & $2.54 \times 10^{-1}$ & $5.64 \times 10^{-6}$ \\
\hline GS5 & $9.91 \times 10^{-5}$ & $1.55 \times 10^{-3}$ & $4.51 \times 10^{-6}$ & $3.19 \times 10^{-4}$ & $1.11 \times 10^{-1}$ & $2.46 \times 10^{-6}$ \\
\hline Average & $1.32 \times 10^{-4}$ & $2.06 \times 10^{-3}$ & $6.00 \times 10^{-6}$ & $6.49 \times 10^{-4}$ & $2.25 \times 10^{-1}$ & $4.99 \times 10^{-6}$ \\
\hline
\end{tabular}

$\mathrm{CDI}_{\mathrm{L}}$ : chronic daily intake lifetime; HQ: hazard quotient; LCR: lifetime cancer risk. 
$1.14 \times 10^{-5}-1.89 \times 10^{-5}$ for FA and $1.60 \times 10^{-6}-4.32 \times 10^{-6}$ for AA, demonstrating that workers in these GS have high inhalation cancer risks, especially considering exposure to FA, which causes nasopharyngeal cancer. The results of the present study indicate that it is necessary to implement self-service systems and vapor recovery technology during the fuel supply activities not yet implemented in Brazil, as well as more rigorous periodic safety training with workers, such as the use of personal protective equipment, accompanied by inspection by the responsible agencies and monitoring of personal exposure, in addition to access to information on the risks of exposure, ${ }^{1,4,56}$ aiming to reduce occupational risks.

It was also observed from the results that both formaldehyde and acetaldehyde presented risk quotient values within the level of acceptability, that is, $\mathrm{HQ}<1$, without indicating non-carcinogenic risks to workers' health due to exposure to each of these individual aldehydes. However, risks due to chronic exposure of workers should be considered. In addition, it is also important to consider the contribution of other VOCs, such as BTEX compounds, also emitted in GS, for a more complete assessment of these risks. ${ }^{1}$

The current Brazilian legislation ${ }^{2}$ determines the location of GS at a minimum distance of $100 \mathrm{~m}$ from residences. Thus, GS in Brazilian urban centers are easily found in and around densely populated areas, which increases the likelihood that people residing near GS are also exposed to FA, AA and other VOCs emissions.

\section{Limitations and uncertainties of the risk assessment}

Uncertainties accompany risk assessment especially when only single point values are used to estimate the risk. ${ }^{34}$ It must also be noted that uncertainties are inherent in quantitative risk assessment, such as: uncertainties in measurement due to the variations in concentrations of the pollutants, uncertainties in values assigned exposure variables (as inhalation rates among individuals), as well as the uncertainties introduced in risk characterization due to day-to-day, place-to-place variations in concentrations. ${ }^{34,66}$ Therefore, the true risk could be either overestimated or underestimated.

The application of passive samplers in the monitoring of gases or vapors, even in occupational environments, offers significant advantages when compared to active techniques, such as small dimensions, low cost, lightweight, silent operation, usually combine the sampling steps with analyte isolation and pre-concentration in a single step and do not require the use of electricity. On the other hand, these samplers show some disadvantages, because they do not provide instantaneous concentrations and they do not distinguish transient episodes of high and low concentrations in a given period. ${ }^{25,42}$ In this study, FA and AA concentrations determined in only one day in each GS during winter were expressed as time-weighted average (TWA) concentrations, considering 8-h periods. Therefore, the exposure levels were based on short-term monitoring, which does not consider potential variations that could exert influence on exposure over prolonged periods.

Therefore, in order to obtain more detailed information on the concentrations of these pollutants and the risks of exposure of workers in these working environments, it would be necessary to carry out sampling involving a larger number of days and at different seasons of the year and to assess the uncertainties in the risk estimates, using a probabilistic approach to risk assessment.

\section{Conclusions}

This study contributed to the monitoring of the air quality in gas stations in the city of Salvador, Bahia, Brazil, with the use of passive sampling, at low cost, allowing the estimation of the non-carcinogenic and carcinogenic risks to workers' health associated with exposure to formaldehyde and acetaldehyde compounds. The FA and AA concentrations did not exceed the maximum limits recommended by NR-15 of the Brazilian Ministry of Labor and Employment, ACGIH and NIOSH for occupational environments, but these exceeded the limit established for FA for long-term exposure in outdoors by TCEQ. This shows that although there is sufficient evidence from studies developed by IARC indicating that exposure to low concentrations, especially FA, can cause different cancers in humans, particularly those associated with the respiratory tract, such as nasopharyngeal cancer, the exposure limits set forth in international and national standards for occupational environments are outdated. For this reason, there is an urgent need for studies to update these limits with more restrictive values, which will certainly contribute to reduce health treatment costs and improve the life quality of GS workers. The values of lifetime cancer risk for the health of the workers in all GS studied, considering 30 years of exposure to FA and AA, were above the acceptable limit of $1.0 \times 10^{-6}$ established by USEPA. These values were 5-10 times higher for FA and 3-8 times higher for AA, showing that gas stations are potentially hazardous sites for the health of workers. Thus, urgent actions are needed to reduce or eliminate the exposure of the workers to these compounds in order to reduce occupational hazards. The results obtained for the non-carcinogenic risks presented values within the level of acceptability $(\mathrm{HQ}<1)$, thereby 
indicating that non-carcinogenic effects on workers' health in the studied GS, taking into account only exposure to these aldehydes, were not observed during the exposure period under consideration.

\section{Acknowledgments}

The authors acknowledge the Coordination for the Improvement of Higher Education Personnel (CAPES) of Brazil (Finance Code 001) and the Federal University of Bahia (UFBA) for fellowships.

\section{References}

1. Cruz, L. P. S.; Alves, L. P.; Santos, A. V. S.; Esteves, M. B.; Gomes, I. V. S.; Nunes, L. S. S.; J. Environ. Prot. 2017, 8, 12.

2. Conselho Nacional do Meio Ambiente (CONAMA); Resolução CONAMA No. 273, de 29 de Novembro de 2000, Estabelece Diretrizes para o Licenciamento Ambiental de Postos de Combustíveis e Serviços e Dispõe sobre a Prevenção e Controle da Poluição dos Postos Revendedores de Combustíveis; Diário Oficial da União, Brasília, seção 1, p. 20-23. Available at http:// www2.mma.gov.br/port/conama/legiabre.cfm?codlegi=271, accessed in December 2019.

3. Agência Nacional de Petróleo, Gás Natural e Biocombustíveis (ANP); Anuário Estatístico Brasileiro do Petróleo, Gás Natural e Biocombustiveis; ANP, Rio de Janeiro, 2018. Available at http://www.anp.gov.br/images/publicacoes/anuarioestatistico/2018/anuario_2018.pdf, accessed in December 2019.

4. Alves, L. P.; Vieira, D. S. P.; Nunes, L. S. S.; Cruz, L. P. S.; Reis, A. C. S.; Gomes, Í. V. S.; Luz, S. R.; Santos, A. V. S.; Esteves, M. B.; J. Environ. Prot. 2017, 8, 650.

5. Cezar-Vaz, M. R.; Rocha, L. P.; Bonow, C. A.; Silva, M. R. S.; Vaz, J. C.; Cardoso, L. S.; Int. J. Environ. Res. Public Health 2012, 9, 2362.

6. Tunsaringkarn, T.; Prueksasit, T.; Kitwattanavong, M.; Siriwong, W.; Sematong, S.; Zapuang, K.; Rungsiyothin, A.; J. Environ. Eng. Ecol. Sci. 2012, DOI 10.7243/2050-1323-1-1.

7. Nespeca, M. G.; Munhoz, J. F. V. L.; Flumignan, D. L.; de Oliveira, J. E.; Fuel 2018, 215, 204.

8. https://www.jusbrasil.com.br/diarios/87237712/dou-secao-106-03-2015-pg-17, accessed in December 2019.

9. Agência Nacional do Petróleo, Gás Natural e Biocombustíveis (ANP); Resolução ANP No. 40, de 25 de Outubro de 2013; Diário Oficial da União (DOU), 28/10/2013; Republicada DOU 30/10/2013. Available at http:// legislacao.anp.gov.br/?path=legislacao-anp/resol-anp/2013/ outubro\&item=ranp-40-2013, accessed in December 2019.

10. Shinohara, N.; Okazaki, Y.; Mizukoshi, A.; Wakamatsu, S.; Chemosphere 2019, 222, 923.
11. Zhang, Y.; Wang, X.; Zhang, Z.; Lü, S.; Shao, M.; Lee, F. S. C.; Yu, J.; Atmos. Environ. 2013, 79, 110.

12. International Agency for Research on Cancer (IARC); IARC Monographs on the Evaluation of Carcinogenic Risks to Humans, vol. 71; World Health Organization: Geneva, 1999. Available at https://monographs.iarc.fr/wp-content/ uploads/2018/06/mono71.pdf, accessed in December 2019.

13. International Agency for Research on Cancer (IARC); IARC Monographs on the Evaluation of Carcinogenic Risks to Humans, vol. 88; World Health Organization: Geneva, 2006. Available at https://monographs.iarc.fr/wp-content/ uploads/2018/06/mono88.pdf, accessed in December 2019.

14. International Agency for Research on Cancer (IARC); IARC Monographs on the Evaluation of Carcinogenic Risks to Humans, vol. 77; World Health Organization: Geneva, 2000. Available at https://monographs.iarc.fr/wp-content/ uploads/2018/06/mono77.pdf, accessed in December 2019.

15. International Agency for Research on Cancer (IARC); IARC Monographs on the Evaluation of Carcinogenic Risks to Humans, vol. 120; World Health Organization: Geneva, 2017. Available at https://publications.iarc.fr/Book-AndReport-Series/Iarc-Monographs-On-The-Identification-OfCarcinogenic-Hazards-To-Humans/Benzene-2018, accessed in December 2019.

16. Manzetti, S.; Andersen, O.; Fuel 2015, 140, 293.

17. Dai, P.; Ge, Y.; Lin, Y.; Su, S.; Liang, B.; Fuel 2013, 113, 10.

18. Schifter, I.; Diaz, L.; Rodriguez, R.; Salazar, L.; Fuel 2011, 90 , 779.

19. Nogueira, T.; Dominutti, P. A.; Carvalho, L. R. F.; Fornaro, A.; Andrade, M. F.; Fuel 2014, 134, 505.

20. Atkinson, R.; Atmos. Environ. 2000, 34, 2063.

21. Rodrigues, M. C.; Guarieiro, L. L. N.; Cardoso, M. P.; Carvalho, L. S.; da Rocha, G. O.; de Andrade, J. B.; Fuel 2012, 92, 258.

22. Corrêa, S.; Arbilla, G.; Atmos. Environ. 2008, 42, 769.

23. de Andrade, M. V.; Pinheiro, H. J. C.; Pereira, P. A.; de Andrade, J. B.; Quim. Nova 2002, 25, 1117.

24. Peng, C. Y.; Yang, H. H.; Lan, C. H.; Chien, S. M.; Atmos. Environ. 2008, 42, 906.

25. Cruz, L. P. S.; Mota, E. R.; Campos, V. P.; Santana, F. O.; Luz, S. R.; Santos, D. F.; J. Braz. Chem. Soc. 2019, 30, 904.

26. Santana, F. O.; Campos, V. P.; Cruz, L. P. S.; Luz, S. R.; Microchem. J. 2017, 134, 78.

27. Nogueira, T.; Dominutti, P. A.; Fornaro, A.; Andrade, M. D. F.; Atmosphere 2017, 8, 144.

28. Corrêa, S.; Arbilla, G.; Martins, E. M.; Quitério, S. L.; Guimarães, C. S.; Gatti, L. V.; Atmos. Environ. 2010, 44, 2302.

29. Pinto, J. P.; Martins, L. D.; da Silva Jr., C. R.; Sabino, C. F.; Amador, I. R.; Solci, M. C.; Atmos. Pollut. Res. 2014, 5, 404.

30. Hadei, M.; Shahsavani, A.; Kermani, M.; Emam, B.; Yarahmadi, M.; Bakhtiari, R.; J. Air Pollut. Health 2018, 3, 63. 
31. Chan, C. S.; Ranasinghe, R. S. A.; Ho, S. S. H.; Ho, K. F.; Yim, S. H. L.; Sugathapalag, A. G. T.; Lee, S. C.; Hung, W. T.; Huang, Y.; Zhang, H.; Atmos. Pollut. Res. 2018, 9, 270.

32. Santana, F. O.; Campos, V. P.; Cruz, L. P. S.; Brito, A. V. S.; Microchem. J. 2019, 147, 524.

33. Delikhoon, M.; Fazlzadeh, M.; Sorooshian, A.; Baghani, A. N.; Golaki, M.; Ashournejad, Q.; Barkhordari, A.; Environ. Pollut. 2018, 242, 938.

34. Du, Z.; Mo, J.; Zhang, Y.; Environ. Int. 2014, 73, 33.

35. U. S. Environmental Protection Agency (USEPA); Determination of Formaldehyde in Ambient Air Using Adsorbent Cartridge Followed by High Performance Liquid Chromatography (HPLC) [Active Sampling Methodology] (EPA/625/R96/010b), $2^{\text {nd }}$ ed.; Compendium Method TO-11A; USEPA: Washington, DC, 1999. Available at https://www3.epa.gov/ ttnamti1/files/ambient/airtox/to-11 ar.pdf, accessed in December 2019.

36. Vasconcellos, P. C.; Carvalho, L. R. F.; Pool, C. S.; J. Braz. Chem. Soc. 2005, 16, 1210.

37. Sousa, F. W.; Cavalcante, R. M.; Rocha, C. A.; Nascimento, R. F.; Ferreira, A. G.; Urban Clim. 2015, 13, 110.

38. Som, D. M.; Dutta, C.; Mukherjee, A. K.; Sen, S.; Transp. Res. Part D 2008, 13, 524.

39. Tunsaringkarn, T.; Morknoy, D.; Siriwong, W.; Prueksasit, T.; Rungsiyothin, A.; Nopparatbundit, S.; J. Health Res. 2012, 26, 155.

40. Tunsaringkarn, T.; Siriwong, W.; Prueksasit, T.; Sematong, S.; Zapuang, K.; Rungsiyothin, A.; Int. J. Sci. Res. Publ. 2012, 2, available at http://www.ijsrp.org/research_paper_jun2012/ ijsrp-June-2012-39.pdf, accessed in December 2019.

41. Kitwattanavong, M.; Prueksasit, T.; Morknoy, D.; Tunsaringkarn, T.; Siriwong, W.; Hum. Ecol. Risk Assess. 2013, 19, 1424.

42. Campos, V. P.; Cruz, L. P.; Godoi, R. H.; Godoi, A. F. L.; Tavares, T. M.; Microchem. J. 2010, 96, 132.

43. Rezende, F. B. F.; Cheibub, A. M. D. S. S.; Netto, A. D. P.; Marques, F. F. C.; Microchem. J. 2017, 134, 383.

44. Baños, C. E.; Silva, M.; Talanta 2009, 77, 1597.

45. https://www.atsdr.cdc.gov/mrls/mrllist.asp\#39tag, accessed in December 2019.

46. https://oehha.ca.gov/chemicals, accessed in December 2019.

47. https://www.epa.gov/iris/basic-information-about-integratedrisk-information-system, accessed in December 2019.

48. World Health Organization (WHO); Environmental Health Criteria 239, Principles for Modelling Dose-Response for the Risk Assessment of Chemicals; WHO: Geneva, Switzerland, 2009. Available at: https://apps.who.int/iris/ handle/10665/43940, accessed in December 2019.

49. U. S. Environmental Protection Agency (USEPA); Guidelines for Human Exposure Assessment; USEPA: Washington, DC, 2016. Available at https://www.epa.gov/sites/production/ files/2016-02/documents/guidelines_for_human_exposure_ assessment_peer_review_draftv2.pdf, accessed in December 2019.

50. U. S. Environmental Protection Agency (USEPA); Risk Assessment Guidance for Superfund, Volume I: Human Health Evaluation Manual (Part F, Supplemental Guidance for Inhalation Risk Assessment) (EPA-540-R-070-002); USEPA: Washington, DC, 2009. Available at https://www.epa.gov/sites/ production/files/2015-09/documents/partf_200901_final.pdf, accessed in December 2019.

51. An, T.; Huang, Y.; Li, G.; He, Z.; Chen, J.; Zhang, C.; Environ. Int. 2014, 73, 186.

52. Zhang, Z.; Yan, X.; Gao, F.; Thai, P.; Wang, H.; Chen, D.; Wang, B.; Environ. Pollut. 2018, 238, 452.

53. U. S. Environmental Protection Agency (USEPA); Integrated Risk Information System (IRIS), Acetaldehyde (CASRN 75-070); USEPA: Washington, DC, 2012. Available at https://cfpub. epa.gov/ncea/iris/iris_documents/documents/subst/0290_ summary.pdf, accessed in December 2019.

54. U. S. Environmental Protection Agency (USEPA); Integrated Risk Information System (IRIS), Formaldehyde (CASRN 50O0-0); USEPA: Washington, DC, 2012. Available at https:// cfpub.epa.gov/ncea/iris/iris_documents/documents/subst/0419_ summary.pdf, accessed in December 2019.

55. http://www.popstoolkit.com/tools/HHRA/SF_USEPA.aspx, accessed in December 2019.

56. Corrêa, S. M.; Arbilla, G.; Marques, M. R. C.; Oliveira, K. M. P. G.; Atmos. Pollut. Res. 2012, 3, 163.

57. http://trabalho.gov.br/seguranca-e-saude-no-trabalho/ normatizacao/normas-regulamentadoras/normaregulamentadora-n-15-atividades-e-operacoes-insalubres, accessed in December 2019.

58. National Institute for Occupational Safety and Health (NIOSH); NIOSH Pocket Guide to Chemical Hazards, Publication No. 2005-149; NIOSH Publications: Cincinnati, Ohio, 2007. Available at https://www.cdc.gov/niosh/docs/2005-149/ pdfs/2005-149.pdf, accessed in December 2019.

59. American Conference of Governmental Industrial Hygienist (ACGIH); Documentation of the Threshold Limit Values and Biological Exposure Indices, $7^{\text {th }}$ ed.; ACGIH: Cincinnati, Ohio, 2016. Available at https://www.acgih.org/forms/ store/ProductFormPublic/search?action $=1 \&$ Product productNumber=0100Doc, accessed in December 2019.

60. https://www.tceq.texas.gov/toxicology/es1/list_main.html, accessed in December 2019.

61. Agência Nacional de Petróleo, Gás Natural e Biocombustíveis (ANP); Dados Estatísticos - Vendas de Derivados de Petróleo e Etanol; ANP: Rio de Janeiro, 2016-2018. Available at http:// www.anp.gov.br/dados-estatisticos, accessed in December 2019.

62. Wang, H. K.; Huang, C. H.; Chen, K. S.; Peng, Y. P.; Aerosol Air Qual. Res. 2010, 10, 559. 
63. Altemose, B.; Gong, J.; Zhu, T.; Hu, M.; Zhang, L.; Cheng, H.; Zhang, L.; Tong, J.; Kipen, H. M.; Ohman-Strickland, P.; Meng, Q.; Robson, M. G.; Zhang, J.; Atmos. Environ. 2015, 109, 61 .

64. Cerón, J. G.; Ramírez, E.; Cerón, R. M.; Carballo, C.; Aguilar, C.; López, U.; Ramírez, A.; Gracia, Y.; Naal, D.; Campero, A.; Guerra, J.; J. Environ. Prot. 2013, 4, 40.
65. Silva, D. B. N.; Martins, E. M.; Corrêa, S. M.; Environ. Monit. Assess. 2017, 188, 289.

66. Guo, H.; Lee, S. C.; Chan, L. Y.; Li, W. M.; Environ. Res. 2004, $94,57$.

Submitted: May 17, 2019

Published online: December 20, 2019 